\title{
Independent predictors of depressive symptoms and social isolation on two-year all-cause mortality among the elderly in a population- based cohort study: gender differences
}

\author{
Hyunsuk Jeong, $\mathrm{PhD}^{1}$; Hyeon Woo Yim, MD, $\mathrm{PhD}^{1 *}$; Beom-Woo Nam, MD, $\mathrm{PhD}^{2}$ \\ ${ }^{1}$ Department of Preventive Medicine, College of Medicine, The Catholic University of Korea, Seoul, Republic of Korea \\ ${ }^{2}$ Department of Psychiatry, School of Medicine, Konkuk University, Chungju Hospital, Chungju, Korea
}

\section{*Corresponding author:}

Name: Hyeon Woo Yim, MD, PhD

Address: Department of Preventive Medicine, College of Medicine, The Catholic University of Korea 222 Banpodero, Seocho gu, Seoul Korea

Tel: $+82-2-2258-7860$

Fax: $+82-2-532-3820$

E-mail: y1693@,catholic.ac.kr

\section{Ethics approval and consent to participate}

Written consent was acquired from all participants following explanation of the nature of the principles of research, including confidentiality and the freedom of choice to participate. This study received full review and approval from the Institutional Review Board of the Catholic University of Korea (CUMC11U035). All procedures were in accordance with the Helsinki Declaration.

\section{Consent for publication}

Not applicable

Availability of data and materials

Datasets generated and/or analyzed during the current study are available from the corresponding author.

\section{Competing interests}

The authors have no competing interests to declare.

\author{
Author Contributions \\ Conceptualization: HJ, HWY \\ Data curation: HJ, BWN \\ Formal analysis: HJ, HWY \\ Funding acquisition: HWY \\ Methodology: HJ, HWY \\ Project administration: $\mathrm{HJ}$ \\ Visualization: HJ \\ Writing - original draft: HJ \\ Writing - review \& editing: HJ, HWY, BWN.
}

\section{Acknowledgement}

We would like to thank the personnel in the Chungju Public Health Center for recruiting the participants and technical assistance for this study

\section{ORCID IDs}

Hyumsuk Jeong: https://orcid.org/0000-0001-5274-3816

Hyeon Woo Yim: https://orcid.org/0000-0002-3646-8161

Beom-Woo Nam: https://orcid.org/0000-0003-3530-1746 
1 Independent predictors of depressive symptoms and social isolation 2 on two-year all-cause mortality among the elderly in a populationbased cohort study: gender differences 


\section{Abstract}

6 Objectives: We investigate whether depressive symptoms and social isolation are independent

7 predictors of two-year all-cause mortality among the elderly using data from a population-

8 based cohort.

9 Methods: A total of 1,033 participants (320 men and 713 women) older than 60 years of age participated in this study. Depressive symptoms, social isolation status, and sociodemographic and health-related covariates were assessed at baseline. The primary outcome measure was two-year all-cause mortality. Data were collected through in-person interviews by trained interviewers. The Genmod procedure was used to calculate relative risks (RRs).

Results: Of the 1,033 participants, 102 (40 men and 62 women) died within a follow-up period of two years. During the two-year follow-up period, $17.8 \%$ of depressed men and $12.3 \%$ of depressed women died, and $29.8 \%$ of socially isolated men and $14.9 \%$ of socially isolated women died. Social isolation was an independent predictor of mortality in old men (adjusted relative risk (aRR): 4.6, 95\% confidence interval (CI): 2.0-10.2), while depressive symptoms were an independent predictor of mortality in old women (aRR: 2.0, 95\% CI: 1.33.6) when controlling potential confounding factors. However, depressive symptoms detected by the geriatric depression scale (GDS) were not associated with mortality in men and social isolation was not associated with mortality in women.

Conclusions:

The effects of depressive symptoms and social isolation on two-year all-cause mortality in an elderly population differed according to gender. It is necessary to develop gender-specific community-based interventions to potentially reduce two-year all-cause mortality in the elderly. 
29 Keywords: depression; social isolation; mortality; cohort; elderly 


\section{Introduction}

The proportion of people aged 65 years and older is expected to increase from $14.9 \%$ in 2019 to $40.1 \%$ in 2060 in South Korea [1]. Such a rapid increase in the older population stands to greatly influence Korean society, requiring that continuous social attention be paid to the older population.

Depression is common and remains a significant problem for older adults with an estimated prevalence of 4-9\% worldwide [2]. In Korea, depression in the elderly has a prevalence of $19.9 \%$ among adults aged 65 years and older [3]. Being diagnosed with a serious medical illness or suffering from a disability increases vulnerability to depression [4]. Psychosocial adversity such as economic impoverishment, isolation, relocation, caregiving, and bereavement contributes to increased susceptibility to depression and/or to triggering depression in the already-vulnerable elderly population [5]. Depression in older adults is associated with emotional suffering, increases in health expenditures, morbidity, higher risk of suicide, and increased mortality from other causes [6].

The number of community-dwelling older adults who live alone has increased globally. According to the Korea Institute for Health and Social Affairs (KIHASA), 23.6\% of Korean older adults are living alone [7]. Living alone directly impacts social isolation in the elderly. Social isolation is particularly problematic in old age due to decreasing economic and social resources, functional limitations, and changes in family structures [8]. Social isolation negatively influences physical and mental health, as well as longevity. A previous metaanalysis has found that social isolation is associated with a $50 \%$ increased risk of developing dementia [9], a 30\% increased risk of incident coronary artery disease or stroke [10], and a $26 \%$ increased risk of all-cause mortality [11].

Previous researches have reported that living alone in men is associated with poorer diet, 
poorer self-rated health, and less help from children [12], and living alone in women is associated with greater financial strain, physical limitations, and more help from children [13].

Although women are socialized to develop a larger and more active social network, potentially protecting them from loneliness [14], it is also clear that women tend to live longer than men and are therefore more likely to be affected by widowhood or more likely to assume the role of caregiver for their spouse. Women's friendships focus on intimacy and disclosure, while men emphasize sociability and an orientation toward tasks or activities [15]. Such differences raise the possibility that the pathways by which social isolation or emotional problems impact mortality risk may differ for men and women. In order to have a better understanding of the association of depression and social isolation with mortality in the elderly, gender difference analyses should be verified for several reasons. Firstly, life expectancy is different between men and women. Secondly, the prevalence of depression and social isolation differs between men and women. Thirdly, women and men build social networks in a different way, such as men experience less intimate relationships than women[16]. Fourthly, it is culturally less acceptable for men to express their emotions than it is for women [17].

In the association of loneliness with health, men generally have more negative attitudes towards care seeking [18]. A previous research has shown that lonely men are more likely to suffer lower life satisfaction and are less resilient than lonely women [19]. The impact of social isolation on mortality might be greater in men because they experience increased inflammatory responses when they are alone than women [20]. Moreover, unhealthy lifestyles including, tobacco and alcohol problems have been associated with loneliness[21], which could explain the stronger loneliness-mortality connection in men than in women. High levels of depressive symptoms are an independent risk factor for mortality in 
community-residing older adults [22]. The mechanisms by which depressive symptoms are associated with mortality may involve restriction of daily activities due to depressive symptoms can contribute to mortality [23]. Depressive symptoms are classified into cognitive-affective symptoms (e.g., anhedonia, negative thoughts, and hopelessness) and somatic symptoms (e.g., fatigue and insomnia). According to a meta-analysis, somatic symptoms of depression are more predictive of mortality than cognitive-affective symptoms[24]. A previous study demonstrated gender differences in symptomatology of depression of the general population in Korea [25]. Female gender showed higher prevalence of somatic symptoms including, fatigue, hypersomnia, and noticeable psychomotor retardation then male gender.

Few longitudinal studies, however, have investigated whether and how depression and social isolation are associated with mortality in older adults and whether those relationships differ by gender. Therefore, we investigate whether depressive symptoms and social isolation are independent predictors of two-year all-cause mortality among the elderly using populationbased cohort data. Because there are differences in individual characteristics according to gender, the size of the effects of depressive symptoms and social isolation on mortality also vary according to gender.

\section{Methods}

\section{Participants}

The population source was all National Basic Living Security Program recipients over 60 years of age in Chungju city, a small town located in the central part of South Korea. At the time of enrollment, the entire population of the target area was 208,202. Among this population, the number of men and women aged 60 or older was 40,196 (19.3\%). Specifically 
in 2011 in the target area, all 1,535 people over 60 years of age were classified as National

Basic Living Security Program recipients. From this we excluded elderly people who were admitted or hospitalized in facilities or hospitals and were unable to communicate due to cognitive impairment. Thus, of 1,535, 1,262 were enrolled in the National Basic Living Security Program Beneficiary cohort. Two-year follow-up surveys were conducted between July and October of 2013. Of the initial 1,262 elderly, 229 were lost to follow-up, with a net total of 1,033 participants (320 men and 713 women) eligible for analysis in the present study. There were no statistical differences between participants and non-participants in age and sex. Informed consent was acquired from all participants following an explanation of the nature of the principles of research, including confidentiality and the freedom of choice to participate. This study received full review and approval from the Institutional Review Board of the Catholic University of Korea (CUMC11U035). All procedures were in accordance with the Helsinki Declaration.

\section{Measurements}

Data on sociodemographic and health-related factors were collected through in-person interviews by trained interviewers. To ensure reliability, the interviewers were trained in interviewing techniques, evaluation, and practical application of assessment tools, together with research ethics at a two-day (16-hour) workshop prior to being put in practice.

\section{Sociodemographic characteristics}

Sociodemographic characteristics, including age (60-74 years versus 75 years and older), sex, years of education, and living situation (e.g., living alone or living with others) were recorded based on participants' responses. Medical comorbidity was assessed by self-reported answers to questions about current medications due to health conditions including hypertension and 
diabetes mellitus.

\section{Geriatric Depression Scale-15}

130 The 15-item geriatric depression scale (GDS-15) is a self-rating scale developed to detect 131 depression and assess the severity of depressive symptoms in the elderly (Brown, 2005).

132 Overall scores of the GDS-15 range from 0 to 15 , with scores for each item based on responses of either yes or no. Higher scores indicate more severe symptoms of depression. The GDS has been found to have $92 \%$ sensitivity and $89 \%$ specificity when evaluated against diagnostic criteria. The validity and reliability of the tool have been supported through both clinical practice and research [26].

Use of the Korean version of the GDS-15 confirmed that the internal consistency was excellent in terms of content and discriminant validity for screening depression among the elderly in the context of the current study. An optimal cutoff score of 10 has been established for the presence of depression [27]. In the current study, depressive symptoms were selfreported with a visiting nurse who assisted in reading the questionnaire from the Korean version of the GDS. The Cronbach's alpha value was found to be 0.88 . We used a threshold score of 10 or higher for dichotomous analyses.

\section{Social isolation}

146 Social isolation was evaluated using an abbreviated version of the Lubben Social Network 147 Scale (LSNS-6), which evaluates social network size among community-dwelling people [28]. This scale consists of six questions, with three questions to assess family ties and three questions to assess friendship ties. A sample question is, "How many relatives do you see or hear from at least once a month?" Responses are measured with scores ranging from none $=0$, 
151 one $=1$, two $=2$, three or four $=3$, five through eight $=4$, and nine or more $=5$. The total score represents a social network size with an equally-weighted sum of the six items, with scores ranging from 0 to 30 [28].

Higher scores represent bigger family-based or friendship-based social networks. For the present study, the LSNS-6 showed acceptable internal consistency with Cronbach's alpha= 0.76. We used the Korean translated version of LSNS-6 [29]. Social isolation can be defined structurally as the absence of social interactions, contacts, and relationships with family and friends and with neighbors on an individual level [30]. Therefore, social isolation was herein identified when respondents answered "none" to all six questions.

\section{Two-year all-cause mortality}

The outcome of this research was two-year all-cause mortality. Death was ascertained by door-to-door visitation of participants' homes. At the two-year follow-up assessment, if death could not be confirmed because a participant no longer resided in the same place as their residence at the time of registration, the case was considered lost to follow-up.

\section{Statistical analysis}

In describing the baseline characteristics of the study population, numerical variables were summarized by their mean and standard deviation, and categorical variables by their count and proportion $(\%)$. Either chi-square or t-test statistics were used to describe differences between men and women. We calculated all-cause mortality during the two-year follow-up period separately for men and women. We investigated the association between depressive symptoms and death (all causes) using the Genmod procedure to calculate relative risks (RRs) for two-year all-cause mortality with a reference category of non-depressive symptoms 
in men and women. In the multivariable model, we adjusted for age in model 2. Model 3 included the variables from model 2 as well as living status, level of education, a diagnosis of hypertension, and a diagnosis of diabetes mellitus at baseline. Similar modeling was carried out for social isolation, using a group with not socially isolated as the reference category. Since depression and social isolation are closely related, we presented the exploratory results of additional adjusting for either social networks or depressive symptoms included the variables from model 3 in model 4. The new concept of an E-value for both the observed association estimate of adjusted relative risk (aRR) and the limit of the confidence interval closest to the null was calculated. The E-value is defined as the minimum strength of association that one or more unmeasured confounders would need to have with both the treatment and the outcome to fully explain away a specific treatment-outcome association, conditional on the measured covariates [31]. All analyses were conducted using statistical (CIs) of risk estimates were reported.

\section{Results}

Baseline sociodemographic characteristics of the 1,033 participants are provided in Table 1; men and women differed significantly for most conditions. More women (46.7\%) than men (31.2\%) were elderly and more women $(58.2 \%)$ than men $(45.3 \%)$ were living alone. Women (61.4\%) more often had hypertension than men (47.5\%) and women had a higher mean score for social network size than men. Male participants had higher levels of education than female participants (Table 1). 
Of 1,033 participants, 102 (40 men and 62 women) had died within the two-year follow-up period. In elderly men, $11.1 \%$ of those without depression died in comparison to $17.8 \%$ of elderly men with depression at baseline. Also in men, $9.5 \%$ of non-socially isolated elderly individuals and $29.8 \%$ of socially isolated elderly individuals at baseline died during the twoyear follow-up period. In elderly women, $6.3 \%$ of those without depression died in comparison to $12.3 \%$ of those with depression at baseline. Also in women, $9.5 \%$ of nonsocially isolated elderly individuals and $14.9 \%$ of socially isolated elderly individuals at baseline died during the two-year follow-up period. The excess occurrence of mortality among depressed men attributable to their depression was 36.4 per 1,000 . This measure among depressed women attributable to their depression was 60.3 per 1,000. The excess occurrence of mortality among socially isolated men attributable to their social isolation was 202.6 per 1,000 , and this measure among socially isolated women attributable to their social isolation was 66.4 per 1,000 (Table 2).

Depressed women had a two-fold increased risk of death (aRR: 2.0, 95\% CI: 1.3-3.6) in comparison to women who did not have significant depressive symptoms after adjusting for potential confounding variables. The point estimate E-value was 3.4 and the confidence 
interval E-value was 1.7. On the other hand, depressive symptoms were not significantly associated with two-year mortality among male participants herein. Social isolation caused a 4.6-fold increased risk of death (aRR: 4.6, 95\% CI: 2.0-10.2) in comparison with the presence of a good social network after adjusting for potential confounding variables in men. The results of additionally adjusting for either social network or depressive symptoms in model 4 were not different from the results of Model 3. The point estimate E-value was 8.7 and the confidence interval E-value was 3.4. On the other hand, social isolation was not significantly associated with two-year mortality among the female participants herein (Table 3).

Table 3 here.

\section{Discussion}

In the current study, the effects of depressive symptoms and social isolation on two-year allcause mortality in elderly individuals differed according to gender. In elderly men, social isolation increased the risk of two-year all-cause mortality by 4.6 times in comparison to those who were not socially isolated. However, GDS-detected depressive symptoms were not associated with two-year all-cause mortality in men.

Social isolation is known to affect health-related physical activity and lifestyles [32]. Socially isolated individuals engage in less physical activity and more sedentary time due to limited access to transportation, reduced contact with friends and family, and living alone [33].

Traditionally, the predominant social role of women was in being housewives, while the social roles of men focused on work and the providing of income and material resources for family maintenance. Considering that participants in the current study are elderly people over 
60 years of age, the older men in our analysis may not have been accustomed to preparing food or doing housework. Thus there is the possibility of a higher risk of malnutrition and dietary inadequacy in older men than in older women in circumstances of social isolation [34]. Also, non-specific and broad social connectedness (as well as social isolation) have been shown to have a greater impact on perceived health in men [35]. In general, men place more emphasis on social connections that provide instrumental support, whereas women tend to seek more emotional support [36]. These findings are consistent with the evidence herein. In men, GDS-detected depression was not associated with two-year all-cause mortality, but social isolation was found to be highly associated with mortality. In order to improve wellbeing in elderly males, it seems that social efforts are needed to improve social isolation. The prevalence of social isolation among elderly males in the current study was $14.7 \%$, which is significant in terms of public health. According to the "2019 Social Isolation Status Analysis" published by the Southeast Regional Statistical Office, about $14 \%$ of the elderly in Korea experience social isolation [7]. The public health implication is that if social isolation prevented from mortality within two years of an initial measure by improving social networks. In elderly women, GDS-detected depressive symptoms increased the risk of two-year allcause mortality by 2.0 times in comparison with individuals without depressive symptoms. However, social isolation was not associated with two-year all-cause mortality in women. The prevalence of social isolation among female elderly participants was $6.6 \%$, which was lower than in male elderly participants (14.7\%). It is known that older women living alone tend to maintain emotional intimacy with friends and neighbors, thus maintaining social bonds better than older men [37]. In women, the effects of social isolation on physical health 
are less than in men because women have self-care abilities due to the lifestyle habits of traditional social roles.

As people grow old, many people experience social isolation due to either a result of living alone, a lack of close family ties, or an inability to participate in community activities. When this occurs in combination with depression are common accompaniment. Social isolation has been reported to be a common comorbidity with depression [38]. Among the elderly men, 122 were positive for depressive symptoms, of which 23 (18.9\%) were socially isolated, and among the elderly women, positive for depressive symptoms was 284, of which 31 (11.9\%) were socially isolated in our sample.

At two-year follow-up, 102 deaths occurred between 2012 and 2013. To compare the mortality rate of the general population, the standardized mortality rate (SMR) was calculated by comparing the 2012-2013 age-specific mortality rate in Korea and 95\% confidence interval of the SMR was obtained by means of the poison distribution method [39]. Compared to the general population, our sample had a slightly higher SMR of 1.06 (95\% CI: 0.85-1.31) (Supplementary table 1). However, the difference was not statistically significant. There is a large body of literature suggesting that women are more susceptible to depressive symptoms than men [40]. The mechanisms behind the differences between men and women are not yet clear, but biological and psychological differences and copying styles in men and women might be explain the reasons [41].

Physician-diagnosed depression is associated with a substantial increase in the risk of mortality, particularly death from cardiovascular disease (CVD) in women [42]. Depressive symptoms detected by GDS have a broader disease entity than major depressive disorder. The prevalence of GDS-detected depressive symptoms in elderly women in this study was $39.8 \%$. 
of association with two-year all-cause mortality herein.

296 According to a report from the "2020 National Survey of Older Koreans", the prevalence of 297 GDS-detected depressive symptoms in the elderly population in Korea was $13.5 \%$ [43]. The 298 public health implication is that if depressive symptoms can be regarded as the cause of 299 mortality in older women and if $10 \%$ of women have depressive symptoms in a group of 30010,000 , then 121 (minimum 72 to maximum 218) older women might be prevented from 301 mortality within two years of an initial measure by managing depressive symptoms.

Our study has several strengths and several potential limitations that need to be acknowledged. Data on sociodemographic and health-related factors were collected through in-person interviews with the use of an easily administered, validated, and standardized tool observational nature of the cohort design, analysis is vulnerable to residual confounding to establish causality. We calculated E-values to assess how robust an association is to potential unmeasured or uncontrolled confounding. In the association between social isolation and allcause mortality in old men, the estimated E-value was 8.67. This suggests that in order to believe that there is no causal relationship between social isolation and all-cause mortality in old men, there would need to be one or more unmeasured confounders that increase the risk of all-cause mortality 8.7 times. Moreover, the estimated E-value was 3.4 in the association between depressive symptoms would need to be one or more unmeasured confounders that increase the risk of all-cause mortality 3.4 times. and all-cause mortality in old women. This suggests that in order to believe that there is no causal relationship between depressive symptoms and all-cause mortality in old women, there These results should be considered in the context of some potential limitations. We obtained 
our data in elderly people exclusively from a sample of National Basic Living Security Program recipients who comprised a group of individuals at high risk for depressive symptoms and social isolation in the community. This should be taken into account when generalizing our results to other populations. Nevertheless, because this study is a cohort study in which the magnitude of the effects is measured in terms of risk ratio, it can be safely assumed that the results would not be different in other populations.

Some symptoms of social isolation and depression overlap, which may result in overestimation of the association between social network size and depression. However, both conditions were measured extensively with well-established and reliable instruments that do not depend on overlapping symptoms. The lost to follow-up rate was $19 \%$ in follow-up assessment herein. Non-participation in surveys throughout the follow-up period could be a source of bias. Regardless, this type of bias is unavoidable in longitudinal studies in aging populations that include only community-dwelling older adults. There were no differences in baseline depressive symptom scores and social network levels between the lost to follow-up and the completed follow-up groups in both men and women. As to way of death ascertainment, it would have been better if objective data were collected by linking the cause of death data from the National Statistical Office. Although the death ascertainment was confirmed by the public health center's list of recipients of basic livelihood benefits, but its accuracy has not been verified, which is a limitation of the current study.

A significant gender by social isolation was seen $(\mathrm{P}=0.037)$. However, gender by depressive symptoms was not reached statistical significance $(\mathrm{P}=0.103)$. The failure of the interaction term to achieve statistical significance may be due inadequate sample size. Since the theory of depression and gender interaction was to be expected, though statistical significance was not reached, analysis was attempted by stratification by gender. The association between 
343 depressive symptoms and 2-year mortality in women shown in this study suggests the

344 possibility that depressive symptoms may increase the risk of death in women than in men.

345 An independent research hypothesis on this topic needs to be confirmed through well-

346 designed further study.

347 From a public health perspective, the findings from the current study suggest that it is

348 necessary to develop gender-specific community-based interventions to mitigate all-cause

349 mortality in older adults. Loneliness-reduction programs can be launched to improve social

350 networks (via the number of relationships) or develop new networks for old men, and social

351 support focusing on interventions to provide emotional security (via intimacy in

352 relationships) for old women may be cultivated to reduce the risk of mortality in both genders.

353 In the meantime, community healthcare professionals are advised to assess social isolation

354 and depression to identify vulnerable older adults for application of existing interventions.

355 Also, older people with depression should be referred for psychiatric, psychological, and

356 social interventions to provide appropriate treatment and potentially reduce mortality. 


\section{References}

359

360

361

362

363

364

365

1. Jang IY, Lee HY, Lee E. Geriatrics Fact Sheet in Korea 2018 From National Statistics. Ann Geriatr Med Res 2019;23:50-53.

2. Casey DA. Depression in Older Adults: A Treatable Medical Condition. Prim Care 2017;44:499-510.

3. Kim GE, Jo MW, Shin YW. Increased prevalence of depression in South Kore a from 2002 to 2013. Sci Rep 2020;10:16979.

4. Behrens-Wittenberg E, Wedegaertner F. Identifying Individuals at High Risk for Permanent Disability From Depression and Anxiety. Front Psychiatry 2020;11: 740.

5. Wilkinson P, Ruane C, Tempest K. Depression in older adults. Bmj 2018;363:k 4922.

6. Zis P, Daskalaki A, Bountouni I, Sykioti P, Varrassi G, Paladini A. Depression and chronic pain in the elderly: links and management challenges. Clin Interv Aging 2017;12:709-720.

7. Affairs KIfHaS. 2019 survey of living conditions and welfare needs of Korean older persons. 2020.

8. Fakoya OA, McCorry NK, Donnelly M. Loneliness and social isolation interve ntions for older adults: a scoping review of reviews. BMC Public Health 2020; 20:129.

9. Kuiper JS, Zuidersma M, Oude Voshaar RC, Zuidema SU, van den Heuvel ER, Stolk RP, et al. Social relationships and risk of dementia: A systematic review and meta-analysis of longitudinal cohort studies. Ageing Res Rev 2015;22:3957.

10. Valtorta NK, Kanaan M, Gilbody S, Ronzi S, Hanratty B. Loneliness and socia 1 isolation as risk factors for coronary heart disease and stroke: systematic revi ew and meta-analysis of longitudinal observational studies. Heart 2016;102:1009 $-1016$.

11. Holt-Lunstad J, Smith TB, Baker M, Harris T, Stephenson D. Loneliness and s ocial isolation as risk factors for mortality: a meta-analytic review. Perspect Ps ychol Sci 2015;10:227-237.

12. Hanna KL, Collins PF. Relationship between living alone and food and nutrient intake. Nutr Rev 2015;73:594-611.

13. Silvaa M, Loureirob, A, Cardoso, G. Social determinants of mental health: a re view of the evidence. Eur J Psychiat 2016;30:259-292.

14. Barreto M, Victor C, Hammond C, Eccles A, Richins MT, Qualter P. Loneline ss around the world: Age, gender, and cultural differences in loneliness. Pers I ndivid Dif 2021;169:110066.

15. Shearer C. More than just talking: the role of self disclosure in the fast friend s procedure: Seton Hall University; 2017.

16. Borys S, Perlman D. Gender Differences in Loneliness. . Personality and Socia 1 Psychology Bulletin 1985;11:63-74.

17. Tijhuis MA, De Jong-Gierveld J, Feskens EJ, Kromhout D. Changes in and fa ctors related to loneliness in older men. The Zutphen Elderly Study. . Age Ag eing 1999;28:491-195.

18. Buffel V, Van de Velde S, Bracke P. Professional care seeking for mental healt $\mathrm{h}$ problems among women and men in Europe: the role of socioeconomic, fam 
ily-related and mental health status factors in explaining gender differences. So c Psychiatry Psychiatr Epidemiol 2014;49:1641-1653.

19. Zebhauser A, Hofmann-Xu L, Baumert J, Häfner S, Lacruz ME, Emeny RT, et al. How much does it hurt to be lonely? Mental and physical differences bet ween older men and women in the KORA-Age Study. Int J Geriatr Psychiatry 2014;29:245-252.

20. Yang YC, McClintock MK, Kozloski M, Li T. Social isolation and adult morta lity: the role of chronic inflammation and sex differences. J Health Soc Behav 2013;54:183-203.

21. Stickley A, Koyanagi A, Roberts B, Richardson E, Abbott P, Tumanov S, et al. Loneliness: its correlates and association with health behaviours and outcomes in nine countries of the former Soviet Union. PLoS One 2013;8:e67978.

22. Brandão DJ, Fontenelle LF, da Silva SA, Menezes PR, Pastor-Valero M. Depre ssion and excess mortality in the elderly living in low- and middle-income cou ntries: Systematic review and meta-analysis. Int J Geriatr Psychiatry 2019;34:22 -30 .

23. Penninx BW. Depression and cardiovascular disease: Epidemiological evidence on their linking mechanisms. Neurosci Biobehav Rev 2017;74:277-286.

24. de Miranda Azevedo R, Roest AM, Hoen PW, de Jonge P. Cognitive/affective and somatic/affective symptoms of depression in patients with heart disease and their association with cardiovascular prognosis: a meta-analysis. Psychol Med 2014;44:2689-2703.

25. Kim JH, Cho MJ, Hong JP, Bae JN, Cho SJ, Hahm BJ, et al. Gender Differe nces in Depressive Symptom Profile: Results from Nationwide General Populati on Surveys in Korea. J Korean Med Sci 2015;30:1659-1666.

26. Brown LM, Schinka JA. Development and initial validation of a 15-item infor mant version of the Geriatric Depression Scale. Int J Geriatr Psychiatry 2005;2 0:911-918.

27. Bae JN, Cho MJ. Development of the Korean version of the Geriatric Depressi on Scale and its short form among elderly psychiatric patients. J Psychosom R es 2004;57:297-305.

28. Lubben J, Blozik E, Gillmann G, Iliffe S, von Renteln Kruse W, Beck JC, et al. Performance of an abbreviated version of the Lubben Social Network Scale among three European community-dwelling older adult populations. Gerontolog ist 2006;46:503-513.

29. Lee H, Kim, SY, Chung, W, Hwang, GS, Hwang YW, Hwang IH. The Validit $\mathrm{y}$ and Reliability of Korean Version of Lubben Social Network Scale. Korean J Fam Med 2009;30:352-358.

30. Umberson D, Montez JK. Social relationships and health: a flashpoint for healt h policy. J Health Soc Behav 2010;51 Suppl:S54-66.

31. VanderWeele TJ, Ding P. Sensitivity Analysis in Observational Research: Introd ucing the E-Value. Ann Intern Med 2017;167:268-274.

32. Holt-Lunstad J, Smith TB. Loneliness and social isolation as risk factors for C VD: implications for evidence-based patient care and scientific inquiry. Heart 2 016;102:987-989.

33. Schrempft S, Jackowska M, Hamer M, Steptoe A. Associations between social isolation, loneliness, and objective physical activity in older men and women. BMC Public Health 2019;19:74. 
34. Boulos C, Salameh P, Barberger-Gateau P. Social isolation and risk for malnutr ition among older people. Geriatr Gerontol Int 2017;17:286-294.

35. McKenzie SK, Collings S, Jenkin G, River J. Masculinity, Social Connectednes s, and Mental Health: Men's Diverse Patterns of Practice. Am J Mens Health 2018;12:1247-1261.

36. Caetano SC, Silva CM, Vettore MV. Gender differences in the association of $\mathrm{p}$ erceived social support and social network with self-rated health status among older adults: a population-based study in Brazil. BMC Geriatr 2013;13:122.

37. Blieszner R, Ogletree AM, Adams RG. Friendship in Later Life: A Research A genda. Innov Aging 2019;3:igz005.

38. Robb CE, de Jager CA, Ahmadi-Abhari S, Giannakopoulou P, Udeh-Momoh C, McKeand J, et al. Associations of Social Isolation with Anxiety and Depressi on During the Early COVID-19 Pandemic: A Survey of Older Adults in Londo n, UK. Front Psychiatry 2020;11:591120.

39. Ulm K. A simple method to calculate the confidence interval of a standardized mortality ratio (SMR). Am J Epidemiol 1990;131:373-375.

40. Liang M, Du B, Zhang H, Lu X, Chen C, Fan C, et al. NLR Is Associated With Geriatric Depression in Chinese Women: A Community-Based Cross-Secti onal Study in Eastern China. Front Psychol 2019;10:2941.

41. Holwerda TJ, van Tilburg TG, Deeg DJ, Schutter N, Van R, Dekker J, et al. I mpact of loneliness and depression on mortality: results from the Longitudinal Ageing Study Amsterdam. Br J Psychiatry 2016;209:127-134.

42. Pan A, Lucas M, Sun Q, van Dam RM, Franco OH, Willett WC, et al. Increa sed mortality risk in women with depression and diabetes mellitus. Arch Gen Psychiatry 2011;68:42-50.

43. AFFAIRS KIFHAS. 2020 National Survey of Older Koreans. In: Affairs KIfHa S, editor.2021. 
482 Table 1. Baseline sociodemographic characteristics and health status of participants (N $483=1,033)$

\begin{tabular}{lccc}
\hline Variables & $\begin{array}{c}\text { Men } \\
(\mathrm{n}=320,31.0 \%)\end{array}$ & $\begin{array}{c}\text { Women } \\
(\mathrm{n}=713,69.0 \%)\end{array}$ & P value \\
\hline Age, years & & & $<.001$ \\
$\quad 60-74$ & $220(68.8)$ & $380(53.8)$ & \\
$\quad 100(31.2)$ & $333(46.7)$ & \\
$\quad$ Level of education & & & \\
$\quad$ None & $51(15.9)$ & $328(46.0)$ & \\
$\quad 1-6$ years & $143(44.7)$ & $313(43.9)$ & \\
$\quad 126(39.4)$ & $72(10.1)$ & \\
Living or more years & & & \\
$\quad$ Alone & $145(45.3)$ & $415(58.2)$ & \\
$\quad$ With others & $175(55.7)$ & $298(41.8)$ & \\
Hypertension & $152(47.5)$ & $438(61.4)$ & $<.001$ \\
Diabetes mellitus & $74(23.1)$ & $160(22.4)$ & 0.808 \\
Depression (GDS-15 $\geq 10)$ & $122(38.1)$ & $284(39.8)$ & 0.604 \\
Social isolation & $47(14.7)$ & $47(6.6)$ & 0.001 \\
\hline Socil isstion
\end{tabular}

484 Social isolation was identified when participants answered "none" to all six questions 
Table 2. Two-year mortality rates according to baseline depression and social isolation in men and women

\begin{tabular}{|c|c|c|c|c|c|c|c|c|c|}
\hline \multirow[b]{2}{*}{ Predictors } & \multirow[b]{2}{*}{ Categories } & \multicolumn{4}{|c|}{$\operatorname{Men}(\mathrm{n}=320)$} & \multicolumn{4}{|c|}{ Women $(\mathrm{n}=713)$} \\
\hline & & $\mathrm{N}$ & Death $(\%)$ & $\begin{array}{c}\text { Incidence } \\
\text { per } 1,000 \text { persons }\end{array}$ & $\mathrm{AR}$ & $\mathrm{n}$ & Death $(\%)$ & $\begin{array}{c}\text { Incidence } \\
\text { per } 1,000 \text { persons }\end{array}$ & AR \\
\hline \multirow[t]{2}{*}{ Depression } & Yes & 122 & $18(17.8)$ & 147.5 & 36.4 & 284 & $35(12.3)$ & 123.2 & 60.3 \\
\hline & No & 198 & $22(11.1)$ & 111.1 & Ref & 429 & $27(6.3)$ & 62.9 & Ref \\
\hline \multirow[t]{2}{*}{ Social isolation } & Yes & 47 & $14(29.8)$ & 297.9 & 202.6 & 47 & $7(14.9)$ & 148.9 & 66.4 \\
\hline & No & 273 & $26(9.5)$ & 95.2 & Ref & 666 & $55(8.3)$ & 82.6 & Ref \\
\hline
\end{tabular}

Depression was identified in cases of Geriatric Depression Scale-15 scores of 10 or above

Social isolation was identified when participants answered "none" to all six questions

AR: attributable risk

Ref: reference 
Table 3. Relative risk of depression and social isolation on two-year mortality in men and women

\begin{tabular}{|c|c|c|c|c|c|c|c|c|}
\hline & \multicolumn{4}{|c|}{ Men } & \multicolumn{4}{|c|}{ Women } \\
\hline & $\begin{array}{c}\text { Model I } \\
\text { RR }(95 \% \mathrm{CI})\end{array}$ & $\begin{array}{c}\text { Model II } \\
\text { RR }(95 \% \mathrm{CI})\end{array}$ & $\begin{array}{c}\text { Model III } \\
\text { RR }(95 \% \mathrm{CI})\end{array}$ & $\begin{array}{c}\text { Model IV } \\
\text { RR }(95 \% \mathrm{CI})\end{array}$ & $\begin{array}{c}\text { Model I } \\
\text { RR }(95 \% \mathrm{CI})\end{array}$ & $\begin{array}{c}\text { Model II } \\
\text { RR }(95 \% \mathrm{CI})\end{array}$ & $\begin{array}{c}\text { Model III } \\
\text { RR }(95 \% \mathrm{CI})\end{array}$ & $\begin{array}{c}\text { Model IV } \\
\text { RR }(95 \% \mathrm{CI})\end{array}$ \\
\hline $\begin{array}{l}\text { Depression } \\
\quad \text { (ref=not depressed })\end{array}$ & $1.4(0.7-2.7)$ & $1.3(0.6-2.6)$ & $1.3(0.6-2.7)$ & $1.2(0.6-2.5)^{*}$ & $2.1(1.2-3.6)$ & $2.2(1.3-3.8)$ & $2.0(1.2-3.6)$ & $2.0(1.2-3.5)^{*}$ \\
\hline E-value (point estimate/CI) & & & & & & & & $3.4 / 1.7$ \\
\hline $\begin{array}{l}\text { No social network } \\
\quad(\text { ref }=\text { not socially isolated }))\end{array}$ & $4.0(1.9-8.4)$ & $4.7(2.1-10.1)$ & $4.6(2.0-10.2)$ & $4.5(1.9-9.9)^{\dagger}$ & $1.9(0.8-4.3)$ & $1.8(0.7-4.0)$ & $1.5(0.6-3.4)$ & $1.2(0.5-2.8)^{\dagger}$ \\
\hline E-value (point estimate/CI) & & & & $8.5 / 3.2$ & & & & \\
\hline
\end{tabular}

Depression was identified in cases of Geriatric Depression Scale-15 scores of 10 or above

Social isolation was identified when participants answered "none" to all six questions

$\mathrm{RR}$ : relative risk

CI: confidence interval

Model I: Crude RR

Model II: Adjusted by age

Model III: Adjusted by age, living status, level of education, diagnosis of hypertension, and diagnosis of diabetes mellitus at baseline

"Model IV: Adjusted by age, living status, level of education, diagnosis of hypertension, diagnosis of diabetes mellitus at baseline, and baseline social network

${ }^{\dagger}$ Model IV: Adjusted by age, living status, level of education, diagnosis of hypertension, diagnosis of diabetes mellitus at baseline, and baseline depressive symptom scores

${ }^{\ddagger}$ Model IV is an exploratory analysis 
Supplementary table 1. Standardized mortality rate in 2012-2013

\begin{tabular}{ccrrrr}
\hline Age group & $\begin{array}{c}\text { No. of death } \\
\text { for 2 years } \\
(2012-2013) \\
\text { within the } \\
\text { cohort }\end{array}$ & $\begin{array}{c}\text { No. of } \\
\text { population } \\
\text { within the } \\
\text { cohort }\end{array}$ & $\begin{array}{c}\text { Age-specific } \\
\text { mortality } \\
\text { rate/100,000 in } \\
\text { Korea }(2012- \\
2013)\end{array}$ & $\begin{array}{c}\text { Age-specific } \\
\text { mortality rate } \\
\text { in Korea } \\
(2012-2013)\end{array}$ & $\begin{array}{c}\text { No. of expected } \\
\text { death in } \\
\text { standard } \\
\text { population }\end{array}$ \\
\hline $70-74$ & 27 & 322 & 3836.2 & 0.038362 & 12.352564 \\
$75-79$ & 19 & 271 & 6909.9 & 0.069099 & 18.725829 \\
$80-84$ & 17 & 177 & 12428 & 0.12428 & 21.99756 \\
$85-89$ & 16 & 85 & 22320 & 0.2232 & 18.972 \\
$90+$ & 10 & 29 & 40301.2 & 0.403012 & 11.687348 \\
\hline Total & 89 & & & & 83.735301 \\
\hline
\end{tabular}

SMR $=1.063(95 \%$ CI: 0.854-1.308, $P=0.297)$ 
Table 1. Baseline sociodemographic characteristics and health status of participants (N $=1,033$ )

\begin{tabular}{|c|c|c|c|}
\hline Variables & $\begin{array}{c}\text { Men } \\
(\mathrm{n}=320,31.0 \%)\end{array}$ & $\begin{array}{c}\text { Women } \\
(\mathrm{n}=713,69.0 \%)\end{array}$ & $P$ value \\
\hline Age, years & & & $<.001$ \\
\hline $60-74$ & $220(68.8)$ & $380(53.8)$ & \\
\hline$\geq 75$ & $100(31.2)$ & $333(46.7)$ & \\
\hline Level of education & & & $<.001$ \\
\hline None & $51(15.9)$ & $328(46.0)$ & \\
\hline $1-6$ years & $143(44.7)$ & $313(43.9)$ & \\
\hline 7 or more years & $126(39.4)$ & $72(10.1)$ & \\
\hline Living status & & & $<.001$ \\
\hline Alone & $145(45.3)$ & $415(58.2)$ & \\
\hline With others & $175(55.7)$ & $298(41.8)$ & \\
\hline Hypertension & $152(47.5)$ & $438(61.4)$ & $<.001$ \\
\hline Diabetes mellitus & $74(23.1)$ & $160(22.4)$ & 0.808 \\
\hline Depression (GDS-15 $\geq 10$ ) & $122(38.1)$ & $284(39.8)$ & 0.604 \\
\hline Social isolation & $47(14.7)$ & $47(6.6)$ & 0.001 \\
\hline
\end{tabular}


Table 2. Two-year mortality rates according to baseline depression and social isolation in men and women

\begin{tabular}{|c|c|c|c|c|c|c|c|c|c|}
\hline \multirow[b]{2}{*}{ Predictors } & \multirow[b]{2}{*}{ Categories } & \multicolumn{4}{|c|}{$\operatorname{Men}(\mathrm{n}=320)$} & \multicolumn{4}{|c|}{ Women $(\mathrm{n}=713)$} \\
\hline & & $\mathrm{N}$ & Death $(\%)$ & $\begin{array}{c}\text { Incidence } \\
\text { per } 1,000 \text { persons }\end{array}$ & $\mathrm{AR}$ & $\mathrm{n}$ & Death $(\%)$ & $\begin{array}{c}\text { Incidence } \\
\text { per 1,000 persons }\end{array}$ & AR \\
\hline \multirow[t]{2}{*}{ Depression } & Yes & 122 & $18(17.8)$ & 147.5 & 36.4 & 284 & $35(12.3)$ & 123.2 & 60.3 \\
\hline & No & 198 & $22(11.1)$ & 111.1 & Ref & 429 & $27(6.3)$ & 62.9 & Ref \\
\hline \multirow[t]{2}{*}{ Social isolation } & Yes & 47 & $14(29.8)$ & 297.9 & 202.6 & 47 & $7(14.9)$ & 148.9 & 66.4 \\
\hline & No & 273 & $26(9.5)$ & 95.2 & Ref & 666 & $55(8.3)$ & 82.6 & $\operatorname{Ref}$ \\
\hline
\end{tabular}

Depression was identified in cases of Geriatric Depression Scale-15 scores of 10 or above

Social isolation was identified when participants answered "none" to all six questions

AR: attributable risk

Ref: reference 
Table 3. Relative risk of depression and social isolation on two-year mortality in men and women

\begin{tabular}{|c|c|c|c|c|c|c|c|c|}
\hline & \multicolumn{4}{|c|}{ Men } & \multicolumn{4}{|c|}{ Women } \\
\hline & $\begin{array}{c}\text { Model I } \\
\text { RR }(95 \% \mathrm{CI})\end{array}$ & $\begin{array}{c}\text { Model II } \\
\text { RR }(95 \% \mathrm{CI})\end{array}$ & $\begin{array}{c}\text { Model III } \\
\text { RR }(95 \% \mathrm{CI})\end{array}$ & $\begin{array}{c}\text { Model IV } \\
\text { RR }(95 \% \mathrm{CI})\end{array}$ & $\begin{array}{c}\text { Model I } \\
\text { RR }(95 \% \mathrm{CI})\end{array}$ & $\begin{array}{c}\text { Model II } \\
\text { RR }(95 \% \mathrm{CI})\end{array}$ & $\begin{array}{c}\text { Model III } \\
\text { RR }(95 \% \mathrm{CI})\end{array}$ & $\begin{array}{c}\text { Model IV } \\
\text { RR }(95 \% \mathrm{CI})\end{array}$ \\
\hline $\begin{array}{l}\text { Depression } \\
\quad \text { (ref=not depressed })\end{array}$ & $1.4(0.7-2.7)$ & $1.3(0.6-2.6)$ & $1.3(0.6-2.7)$ & $1.2(0.6-2.5)^{*}$ & $2.1(1.2-3.6)$ & $2.2(1.3-3.8)$ & $2.0(1.2-3.6)$ & $2.0(1.2-3.5)^{*}$ \\
\hline E-value (point estimate/CI) & & & & & & & & $3.4 / 1.7$ \\
\hline $\begin{array}{l}\text { No social network } \\
\quad(\text { ref }=\text { not socially isolated }))\end{array}$ & $4.0(1.9-8.4)$ & $4.7(2.1-10.1)$ & $4.6(2.0-10.2)$ & $4.5(1.9-9.9)^{\dagger}$ & $1.9(0.8-4.3)$ & $1.8(0.7-4.0)$ & $1.5(0.6-3.4)$ & $1.2(0.5-2.8)^{\dagger}$ \\
\hline E-value (point estimate/CI) & & & & $8.5 / 3.2$ & & & & \\
\hline
\end{tabular}

Depression was identified in cases of Geriatric Depression Scale-15 scores of 10 or above

Social isolation was identified when participants answered "none" to all six questions

$\mathrm{RR}$ : relative risk

CI: confidence interval

Model I: Crude RR

Model II: Adjusted by age

Model III: Adjusted by age, living status, level of education, diagnosis of hypertension, and diagnosis of diabetes mellitus at baseline

*Model IV: Adjusted by age, living status, level of education, diagnosis of hypertension, diagnosis of diabetes mellitus at baseline, and baseline social network

${ }^{\dagger}$ Model IV: Adjusted by age, living status, level of education, diagnosis of hypertension, diagnosis of diabetes mellitus at baseline, and baseline depressive symptom scores

${ }^{\ddagger}$ Model IV is an exploratory analysis 